\title{
COST, PREVALENCE AND CORRELATES OF CIGARILLO USE IN 28 EUROPEAN COUNTRIES IN 2017
}

\author{
Filippos T. Filippidis ${ }^{1,2}$, Enkeleint A. Mechili ${ }^{3}$, Charis Girvalaki ${ }^{4}$, Constantine Vardavas $2,4,5$ \\ ${ }^{1}$ Department of Primary Care and Public Health, School of Public Health, Imperial College, London, United Kingdom \\ ${ }^{2}$ Centre for Health Services Research, School of Medicine, National and Kapodistrian University of Athens, Athens, Greece \\ ${ }^{3}$ Department of Health Care, Faculty of Public Health, University of Vlora, Vlora, Albania \\ ${ }^{4}$ Laboratory of Toxicology, Medical School, University of Crete, Rethymnon, Greece \\ ${ }^{5}$ European Network for Smoking and Tobacco Prevention, Brussels, Belgium
}

\section{SUMMARY}

Objectives: Although manufactured cigarettes remain the most popular tobacco product worldwide, the use of other products, including little cigar and cigarillo, has been rising in recent years; however, there is a paucity of data on the correlates of current and ever use of cigarillos in Europe. The aim of this study was to explore the extent and determinants of cigarillo use, as well as to describe the cost and affordability of cigarillos across the EU, in light of the current regulatory framework at a European level.

Methods: We performed a secondary analysis of data collected across 28 European Union (EU) Member States through wave 87.1 of the Eurobarometer survey, conducted in March 2017 ( $N=27,901)$. A multilevel logistic regression model was fitted to assess the association of current and ever cigarillo use with the above socio-demographic factors. We also analysed Euromonitor International data on cigarillo prices in 2017 from 24 EU Member States.

Results: Across the EU, $0.46 \%$ (95\% Cl: $0.33-0.63$ ) of those aged $\geq 15$ years reported at least weekly current use of cigarillos in 2017 , which corresponds to 1,966,516 (95\% Cl: 1,426,554-2,709,563) people. Finland recorded the highest prevalence (20.51\%) of ever cigarillo use in Europe while Ireland had the lowest $(1.15 \%)$. Male sex, living in urban area and being over 55 years old compared to $15-24$ year olds were associated with greater odds of ever cigarillo use. Median cigarillo prices varied widely, ranging from 3.60 Euros in Portugal to 20.40 Euros in Bulgaria per 20 sticks.

Conclusions: The use of cigarillos in Europe is associated with several socio-demographic factors such as gender, age and living area. Policy makers of EU countries, especially now under the regulatory framework of the EU Tobacco Products Directive, should work together to enforce more restrictive rules for cigarillos.

Key words: cigarillos, Europe, epidemiology, Eurobarometer

Address for correspondence: E. A. Mechili, Department of Health Care, Faculty of Public Health, University of Vlora, Vlora, Kosova Street, P. Box 9401, Vlora, Albania. E-mail: mechili@univlora.edu.al

https://doi.org/10.21101/cejph.a5583

\section{INTRODUCTION}

In recent years, tobacco control efforts have been successful in the European region (1) and cigarette use in Europe and the United States (US) has decreased $(2,3)$, but at the same time the use of other products such as little cigars and cigarillos continues to rise (4). Data for the European Union (EU) have revealed that although only $1 \%$ of smokers smoke cigarillos, cigars or pipes on a daily basis, $8 \%$ of them use these products occasionally or have tried them in the past (3). Cigarillos are usually 100-110 $\mathrm{mm}$ long and $10-12 \mathrm{~mm}$ in diameter, while distinguished from other cigar products based on their tobacco content weight: $3-10 \mathrm{lbs} / 1,000$ units (1.360-4.536 kg/1,000 units) for cigarillos vs $<3 \mathrm{lbs} / 1,000$ units ( $<1.360 \mathrm{~kg} / 1,000$ units) for little cigars and $>10 \mathrm{lbs} / 1,000$ units (4.536 kg/1,000 units) for large cigars (5). In contrast to normal cigars, cigarillos are generally less expensive, machine-made and similar in size to a cigarette (6).
It is essentially a "miniature cigar" and can be consumed in a short period (7).

In a study conducted by $\mathrm{Vu}$ et al. (8), flavours/tastes, easy environmental access and/or low costs are among the key reasons for initiation of alternative tobacco products. Cigarillos are often more used by young and less educated population (3). Previous research has indicated that in the US, males, young adults, African Americans, those of lower socioeconomic status, and current users of other tobacco products are more likely to use little cigars and cigarillos (4). A study in Canada reported that $14.8 \%$ of students in grades 10-12 are using flavoured tobacco (9). However, studies with individual level data are scarce and little research has been done to evaluate the parameters related to cigarillo use in areas other than the US. Their low price, burn time and flavourings render them attractive as substitutes to manufactured cigarettes, especially for young and minority population users, the vast majority of whom do not consider themselves addicted 
(4). Despite that, tobacco control policies in the US and Europe are lacking or at least do not apply equally to cigarettes and little cigars/cigarillos $(10,11)$. Under the current regulatory framework of the EU Tobacco Products Directive, although cigarettes are required to be sold in packs of at least 20 sticks, cigarillos may be sold in smaller pack sizes, with no regulation of the number of sticks per pack and no regulation of potential characterising flavours (10-12). Additionally, taxation for cigars/cigarillos is lower (13), which makes cigarillo an alternative option of lower cost for smokers $(14,15)$.

Hence, the aims of this study were to explore the extent and determinants of cigarillo use, as well as to describe the cost and affordability of cigarillos across the EU, in light of the current regulatory framework at a European level.

\section{MATERIALS AND METHODS}

\section{Euromonitor}

We obtained data on cigarillo retail prices from Euromonitor International (16). Euromonitor International is a private company which collects market data for multiple products. Tobacco products prices are collected annually from multiple retail sources in each country with the aim to cover the most popular products in each category. Although the primary purpose of the dataset is commercial, Euromonitor data have been previously used in tobacco research $(17,18)$. We used retail price data collected in December 2017 in 24 Member States (MS). Data were not available for Luxembourg, Cyprus, Belgium and Malta. Prices per pack were recorded in local currencies; we transformed all prices into Euros $(€)$ using exchange rates on the 1st December, 2017 and estimated the price of a 20 -stick pack to account for variable pack sizes. Affordability of cigarillos was estimated adapting the Relative Income Price (RIP) measure (19). RIP is a widely used measure of the affordability of tobacco products. For cigarettes, the RIP reflects the percentage of the Gross Domestic Product (GDP) per capita which is required to purchase 100 packs of cigarettes in a certain country. We obtained data on GDP per capita from Eurostat (20). To calculate the RIP for cigarillos, we multiplied the median price of the 20 -stick pack we calculated in each country by 100 and expressed this amount as a percentage of the GDP per capita.

\section{Eurobarometer \\ Data Source}

We conducted a secondary analysis of data collected through wave 87.1 of the Eurobarometer survey, conducted in March 2017 $(\mathrm{N}=27,901)$. Tobacco-related Eurobarometer surveys, which are commissioned and funded by the European Commission have been conducted in previous years as well, but no comparable individual questions on cigarillo use were included before 2017. Eurobarometer surveys follow a standard sampling methodology: Primary Sampling Units (PSU) are selected in each country, proportional to population size. Subsequently, a sample of starting addresses is randomly selected in each PSU, and households are systematically selected (every Nth address) with a standard random route starting from these initial addresses. One consenting participant aged $\geq 15$ years (the one whose birthday is closest to the interview date) is selected in each household and interviewed in their national language; all data are self-reported. Eurobarometer does not publish response rates, but post-stratification and population size weighting based on Eurostat data were applied to ensure that samples were representative at the member state and at the EU-level in terms of age, gender and area of residence. Eurobarometer datasets are freely available online. Further details on the sampling and interview methodology are reported in the official Eurobarometer report (21). We analysed data from all 28 EU MS.

\section{Cigarillo Use}

Respondents were asked a series of questions about their smoking behaviour. Those who reported having tried a tobacco product, even once or twice, were further asked to report how often they use or used a number of products, including cigarillos. Responses included "every day", "every week", "every month", "less than monthly", "you have tried only once or twice", and "never". Respondents who reported having used cigarillos once or twice, less than monthly, every month, every week or every day were considered ever users of cigarillos. Those currently using cigarillos every day or every week were classified as current users.

\section{Socio-demographic Data}

Data were collected on participants' age (15-24, 25-39, $40-54$ and $\geq 55$ years), sex (male, female), area of residence (rural, urban), and education (the age when they stopped full-time education: $\leq 15,16-19$ or $\geq 20$ years old). Eurobarometer does not include a question on income, but we used responses to the question "During the last twelve months, would you say you had difficulties to pay your bills at the end of the month?" to classify participants into those who had financial difficulties (i.e. those who responded "most of the time" or "from time to time") and those who had no difficulties ("almost never/never").

\section{Statistical Analysis}

We report median prices of cigarillos per 20 sticks, as well as minimum and maximum prices by country. Descriptive Eurobarometer results are presented as percentages (\%) with 95\% CI, while logistic regression results are presented as adjusted Odds Ratios (aOR) with 95\% CI. We fitted a multilevel logistic regression model, allowing for clustering at the EU MS level, to assess the association between ever use of cigarillos and socio-demographic factors, including age, sex, area of residence, education, and financial difficulties. A similar multilevel logistic regression model was fitted to assess the association between current cigarillo use and the same sociodemographic factors. We used Bayesian Information Criterion and Akaike Information Criterion to decide the optimal model specifications. We also calculated the Spearman's correlation coefficient between prevalence of ever use and RIP at the country level. All analyses were performed with Stata 14.0 (StataCorp). Weights provided in the official Eurobarometer datasets were used in all descriptive analyses to account for the complex design of the survey and to estimate numbers of users at the EU level. 


\section{RESULTS}

The Euromonitor sample consisted of 256 observations across the $24 \mathrm{MS}$, a mean of 10.7 products samples in each country. Median retail prices per 20 sticks varied widely, ranging from $€ 3.60$ in Portugal and $€ 4.75$ in Spain to $€ 20.40$ in Bulgaria and $€ 33.41$ in Slovakia. This variation was reflected in affordability as well. Cigarillos were most affordable in Portugal ( $\mathrm{RIP}=1.57 \%)$ and the Netherlands $(\mathrm{RIP}=1.62 \%)$ and less affordable in Slovakia $(\mathrm{RIP}=14.53 \%)$ and Bulgaria (13.87\%). Similar variation was observed within MS as well (Table 1, Figure 1).

The prevalence of ever cigarillo use among people $\geq 15$ years old in the 28 EU MS, in 2017 is presented in Table 1 and Figure 1. Finland had the highest prevalence $(20.51 \%)$ of ever cigarillo use while Ireland had the lowest (1.15\%). There was great variation of ever use among the EU MS with Finland, Greece (17.40\%) and Austria (16.31\%) among those with the highest prevalence. However, Ireland, Italy (2.65\%) and Portugal (2.89\%) were among the countries with the lowest prevalence of ever use. Only 105 respondents reported current daily or weekly use of cigarillos in the entire sample, therefore no country-specific estimates for current use are presented. Prevalence of ever use was not statistically significantly correlated with RIP $(\mathrm{p}=0.476)$.

Across the EU, $0.46 \%$ (95\% CI: $0.33-0.63$ ) of those aged $\geq 15$ years reported at least weekly current use of cigarillos in 2017, which corresponds to $1,966,516$ (95\% CI: 1,426,554-2,709,563) people. In the same year, 6.35\% (95\% CI: 5.91-6.82) of EU inhabitants aged $\geq 15$ years had ever used cigarillos, which corresponds to $27,311,431$ people $(95 \%$ CI: $25,397,657-29,358,917)$ (Table 1$)$.

Table 2 describes the association of several demographic variables with ever and current use of cigarillos in 28 EU Member States in 2017. Compared to females, male Europeans were more

Table 1. Retail prices, affordability and prevalence of ever cigarillo use among people $\geq 15$ years old in 28 European Union Member States in $2017(N=27,901)$

\begin{tabular}{|c|c|c|c|}
\hline & $\begin{array}{l}\text { Ever use } \\
\%(95 \% \mathrm{Cl})\end{array}$ & $\begin{array}{l}\text { Retail price in Euros } \\
\text { median (range) }\end{array}$ & $\begin{array}{c}\text { RIPa } \\
\%\end{array}$ \\
\hline Austria & $16.31(13.94-19.00)$ & $10.10(5.94-18.60)$ & 2.64 \\
\hline Belgium & $7.3(5.83-9.09)$ & $\mathrm{n} / \mathrm{a}$ & $\mathrm{n} / \mathrm{a}$ \\
\hline Bulgaria & $5.14(3.93-6.70)$ & $20.40(15.34-32.62)$ & 13.87 \\
\hline Croatia & $5.96(4.62-7.67)$ & 8.67 (6.88-28.31) & 4.74 \\
\hline Cyprus & $8.12(5.90-11.07)$ & $\mathrm{n} / \mathrm{a}$ & $\mathrm{n} / \mathrm{a}$ \\
\hline Czech Republic & $11.36(9.42-13.64)$ & $10.20(6.49-17.19)$ & 3.85 \\
\hline Denmark & $6.32(5.03-7.91)$ & $8.26(5.14-21.50)$ & 2.21 \\
\hline Estonia & $10.59(8.42-13.24)$ & $13.85(10.80-17.98)$ & 6.00 \\
\hline Finland & $20.51(17.90-23.39)$ & $10.98(3.53-15.60)$ & 3.37 \\
\hline France & $7.98(6.24-10.16)$ & $8.80(8.00-9.00)$ & 2.82 \\
\hline Germany & $9.27(7.72-11.09)$ & $6.50(2.82-6.80)$ & 1.77 \\
\hline Greece & $17.40(15.03-20.05)$ & $7.00(2.35-27.00)$ & 3.48 \\
\hline Hungary & $3.18(2.17-4.64)$ & $4.77(1.65-10.83)$ & 2.34 \\
\hline Ireland & $1.15(0.67-1.95)$ & $17.4(12.50-20.80)$ & 3.15 \\
\hline Italy & $2.65(1.83-3.83)$ & $6.67(1.80-16.60)$ & 2.32 \\
\hline Latvia & $9.99(7.62-12.99)$ & $6.58(3.17-10.98)$ & 3.27 \\
\hline Lithuania & $5.05(3.66-6.93)$ & $6.85(2.35-21.96)$ & 2.93 \\
\hline Luxembourg & $6.83(4.72-9.78)$ & $\mathrm{n} / \mathrm{a}$ & $\mathrm{n} / \mathrm{a}$ \\
\hline Malta & $3.57(2.00-6.28)$ & n/a & $\mathrm{n} / \mathrm{a}$ \\
\hline Netherlands & $5.03(3.86-6.54)$ & $6.20(3.20-7.60)$ & 1.62 \\
\hline Poland & $5.28(4.00-6.92)$ & $9.49(4.74-15.66)$ & 4.54 \\
\hline Portugal & $2.89(2.00-4.16)$ & $3.60(3.29-5.20)$ & 1.57 \\
\hline Romania & $6.53(5.19-8.18)$ & $13.81(4.32-69.05)$ & 7.38 \\
\hline Slovakia & 3.19 (2.19-4.64) & $33.41(15.00-84.00)$ & 14.53 \\
\hline Slovenia & $3.42(2.31-5.03)$ & $13.60(2.59-27.20)$ & 5.35 \\
\hline Spain & $4.12(2.86-5.89)$ & $4.75(1.20-15.60)$ & 1.71 \\
\hline Sweden & $13.12(10.45-16.35)$ & $11.04(2.01-18.07)$ & 3.03 \\
\hline United Kingdom & $3.14(2.26-4.36)$ & $12.59(12.02-12.91)$ & 4.00 \\
\hline EU & 6.35 (5.91-6.82) & & \\
\hline
\end{tabular}

${ }^{\mathrm{a} R I P}$ - Relative Income Price based on median cigarillo prices 


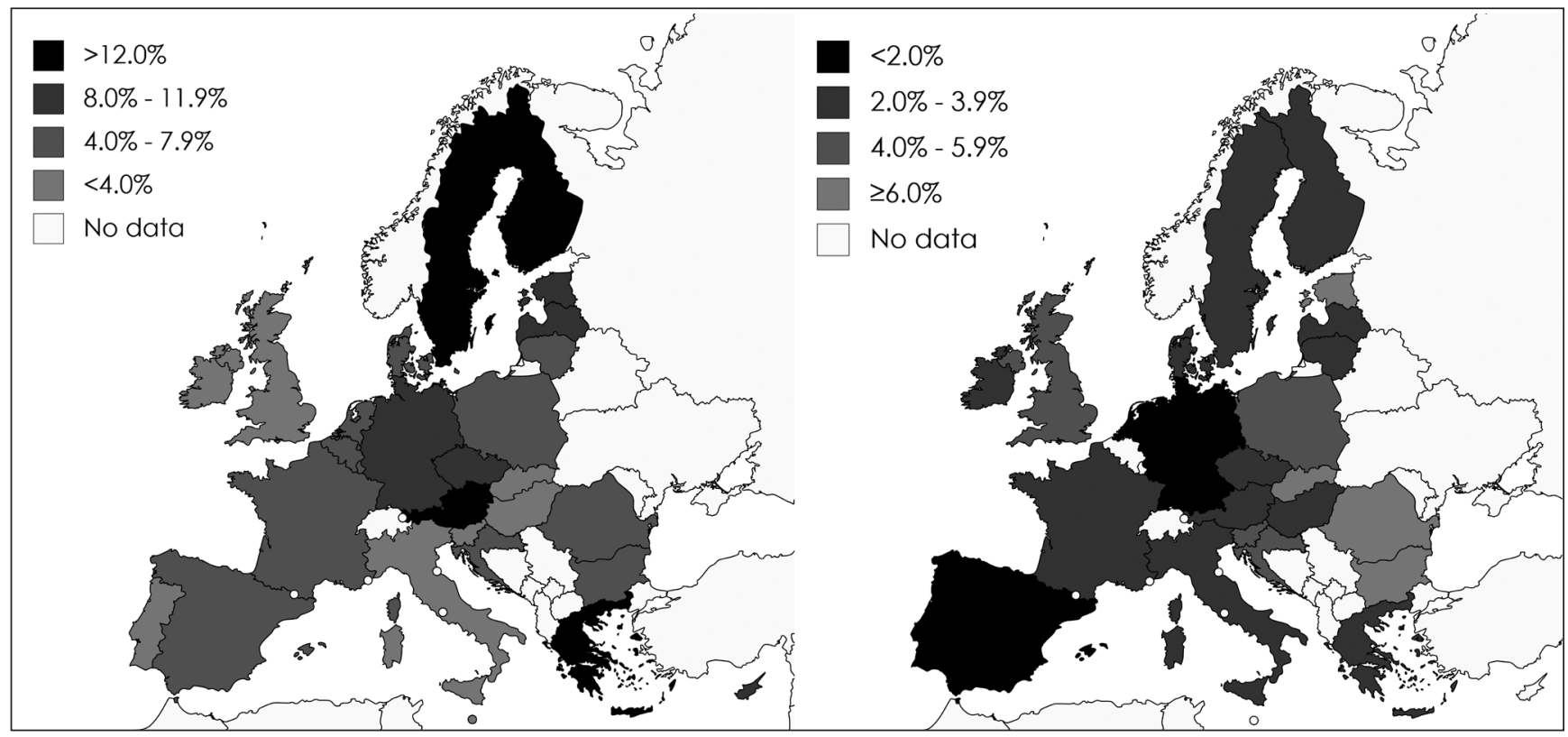

Fig. 1. Prevalence of ever use (left) and affordability - RIP (right) of cigarillos in the European Union, 2017.

RIP - Relative Income Price based on median cigarillo prices

Maps created with mapchart.net.

likely to have ever used cigarillos $(\mathrm{OR}=4.57 ; 95 \% \mathrm{CI}: 4.10-5.11)$ or be current users $(\mathrm{OR}=4.39 ; 95 \% \mathrm{CI}: 2.75-7.00)$. Compared to people who stopped full-time education below the age of 16 , those who stopped education between 16-19 years of age were

Table 2. Factors associated with ever and current use of cigarillos in 28 EU Member States in 2017

\begin{tabular}{|c|c|c|}
\hline & $\begin{array}{l}\text { Ever cigarillo use } \\
\text { AOR }^{*}(95 \% \mathrm{Cl})\end{array}$ & $\begin{array}{c}\text { Current cigarillo } \\
\text { use } \\
\text { AOR }^{*}(95 \% \mathrm{Cl})\end{array}$ \\
\hline \multicolumn{3}{|l|}{ Sex } \\
\hline Female (ref) & 1.00 & 1.00 \\
\hline Male & $4.57(4.10-5.11)$ & $4.39(2.75-7.00)$ \\
\hline \multicolumn{3}{|l|}{ Age (years) } \\
\hline$\geq 55$ (ref) & 1.00 & 1.00 \\
\hline $40-54$ & $1.10(0.97-1.24)$ & $0.87(0.54-1.39)$ \\
\hline $25-39$ & $1.14(1.00-1.30)$ & $0.63(0.36-1.10)$ \\
\hline $15-24$ & $0.71(0.58-0.87)$ & $0.08(0.01-0.59)$ \\
\hline \multicolumn{3}{|l|}{ Education (age at completion) } \\
\hline$\leq 15$ (ref) & 1.00 & 1.00 \\
\hline $16-19$ & $1.29(1.10-1.52)$ & $1.38(0.73-2.62)$ \\
\hline$\geq 20$ & $1.43(1.22-1.69)$ & $1.69(0.88-3.27)$ \\
\hline \multicolumn{3}{|l|}{ Area of residence } \\
\hline Rural & 1.00 & 1.00 \\
\hline Urban & $1.23(1.10-1.37)$ & $1.16(0.75-1.79)$ \\
\hline \multicolumn{3}{|l|}{ Difficulty in paying bills } \\
\hline Almost never/never (ref) & 1.00 & 1.00 \\
\hline $\begin{array}{l}\text { From time to time/ most of } \\
\text { the time }\end{array}$ & $1.41(1.25-1.58)$ & $1.87(0.21-2.90)$ \\
\hline
\end{tabular}

1.29 (95\% CI: $1.10-1.52)$ times more likely to be ever users while those who stopped when they were $\geq 20$ years old, 1.43 times $(95 \%$ CI: 1.22-1.69). Urban area of residence was also associated with greater odds of ever cigarillo use $(\mathrm{OR}=1.23$; 95\% CI: $1.10-1.37)$, compared to living in rural areas. Finally, people with difficulty in paying bills from time to time or most of the time were more likely to be ever users compared to those who never or almost never had problems $(\mathrm{OR}=1.41 ; 95 \% \mathrm{CI}$ : $1.25-1.58)$. Younger participants (15 to 24 years old) were less likely to report ever $(\mathrm{OR}=0.71 ; 95 \% \mathrm{CI}: 0.58-0.87)$ or current $(\mathrm{OR}=0.08 ; 95 \% \mathrm{CI}$ : $0.01-0.59)$ cigarillo use compared to those aged 55 years or more.

\section{DISCUSSION}

Our study revealed that while the prevalence of cigarillo ever use in the EU is generally low, there is a wide variation among EU MS. Similarly, median cigarillo prices and affordability varied among EU MS. We also identified several factors associated with ever use such as elder age, male gender, educational level, urban residence, and difficulty in paying bills.

To our knowledge this is the first study trying to identify the burden of cigarillo use in the EU. Largely similar to previous research, we found that cigarillo users were more likely to be male, of lower income or less educated $(4,6)$. In the US, people living in the South are more likely to be cigarillo smokers (4). However, comparison with south EU countries is difficult to be conducted in this case. Several studies conducted in the US and Canada indicate that little cigars/cigarillos/flavoured tobacco may be a threat to public health as they are mostly used by males, young adults or adolescents and as a cheaper substitute for cigarettes (4, $6,9)$. In contrast to other studies (3), our results indicated that adolescents over 15 years of age and young adults were less likely to be either ever or current smokers of cigarillos when compared to older adults in the EU, which may suggest differences in culture 
or/and market characteristics between the EU and the US. One of the main concerns regarding cigarillos is that, due to flavourings and lower cost, they might be attractive to adolescents who are at risk of becoming smokers, an area that warrants further research, especially within the European context $(4,6)$.

Despite the relatively low prevalence of cigarillo use in the EU (in the US, $3.8 \%$ of males and $1.9 \%$ of females are current users of little cigars or cigarillos) (4), the current favourable taxation of cigarillos could facilitate a rise in cigarillo use or dual use with cigarettes $(5,21)$, as poly-tobacco use is quite frequent in European countries (22). Currently, across the EU, cigarillos are subject to different taxation regulation than cigarettes, making them cheaper than cigarettes even within the same brand (14). This price edge could potentially enable brand-loyal cigarette smokers to stick to their usual brand despite rising cigarette taxes. Variations in the magnitude of price differences between different tobacco products, as well as in tobacco control policies and market characteristics could, at least in part, explain the differences in cigarillo popularity across EU as noted within our analysis.

To our knowledge, this is the first study to report cost of cigarillos across multiple EU MS and to estimate their affordability within each country. Although comparisons with cigarette prices are not straightforward, due to the potentially different patterns of use and variable tobacco and nicotine content per stick, our findings may inform further research and national regulatory and taxation policies. It is noteworthy that cigarillo prices do not seem to follow the same pattern as cigarette prices in Europe. In particular, MS where cigarettes are among the cheapest in the EU, such as Bulgaria, Romania, Estonia and Slovakia, had some of the highest median cigarillo prices (17). This may reflect differences in taxation schemes, but could also be related to different marketing strategies of the tobacco industry. Cigarillos may be marketed as luxurious, high-end products in certain markets and as affordable alternatives to boxed cigarettes in others.

Tobacco control efforts made by both individual countries and the European Union as a whole have been effective in reducing smoking prevalence, tobacco-related mortality and healthcare expenses in the EU $(23,24)$. Despite the increased attention that European policymakers have shown in tobacco, little cigar and cigarillos are not covered by the same regulations as boxed cigarettes and have favourable packaging legislation, text only warning labels and can be sold still in smaller packages of 10 (11). It must be noted that at the EU level, pictorial warnings on cigarette packs have been found to positively impact smokers' behaviour towards making a quit attempt or reducing the number of cigarettes smoked per day, compared to text-only warning labels (24). Moreover, internal tobacco industry research over the years has also revealed that smaller cigarette packages are deemed more attractive to young adults $(25,26)$ and hence the current packaging of cigarillos may have a similar effect in influencing their behaviour towards increased cigarillo use.

We analysed Eurobarometer data, collected using consistent sampling methodology and questionnaires, making findings comparable across the EU. The sample was representative of the general population and large overall; however, current cigarillo use overall was rare which precluded country-specific analyses on this dataset. All data were self-reported and could not be validated with objective measurements while the question assessing cigarillo use was not consistent with previous Eurobarometer surveys; hence we could not assess trends in cigarillo use over time. Regarding price data, the number of data points in some MS was relatively small and findings may not fully reflect the cigarillo products available in all markets. However, considering the scarcity of data on the subject, this analysis provides important insights into the European cigarillo market.

The current study is the first (to our best knowledge) that reports the cost of cigarillos among EU countries and one of the few to study cigarillo use in Europe. We used data from the Eurobarometer survey. Although response rates were not made available, Eurobarometer uses a standardized methodology across countries and allows for direct and meaningful comparisons within the EU. We had no data on the role of flavours in cigarillo use, which may be an important element of the issue. Additionally, our analysis accounted neither for nuanced differences in legislation among EU countries, nor for cultural differences and characteristics of national tobacco markets. In addition, retail price data were missing for 4 EU MS. Despite the limitations, the present study can serve as baseline for future research in this field.

\section{CONCLUSIONS}

This study comes to fill a gap in the literature by exploring the cost of cigarillos and the extent of cigarillos use in Europe in association with several socio-demographic factors. Our findings indicated that there is a wide variation in both the prevalence of cigarillo ever use and the median cigarillo prices in the EU while cigarillos are generally affordable in most countries. We also identified several factors associated with ever use such as older age, male gender, educational level, urban residence and difficulty in paying bills. These parameters should be evaluated in light of the current regulative measures, which under the Tobacco Products Directive, are more favourable for little cigars/cigarillos compared to manufactured cigarettes. Further research and monitoring is warranted so as to evaluate potential future changes in tobacco product use in the EU.

\section{Funding}

This work was supported by a grant from the European Commission (Horizon 2020 HCO-6-2015; EUREST-PLUS: 681109; Vardavas).

\section{Conflict of Interests}

None declared

\section{REFERENCES}

1. Glahn A, Kyriakos CN, Radu Loghin C, Nguyen D, Starchenko P, Jimenez-Ruiz C, et al. Tobacco control achievements and priority areas in the WHO Europe Region: A review. Tob Prev Cessat. 2018;4:15. doi: org/10.18332/tpc/89925.

2. Agaku IT, King BA, Dube SR; Centers for Disease Control and Prevention (CDC). Current cigarette smoking among adults - United States, 2005-2012. MMWR Morb Mortal Wkly Rep. 2014;63(2):29-34.

3. Attitudes of Europeans towards tobacco and electronic cigarettes: report. Special Eurobarometer 458 [Internet]. European Union; 2017 [cited 2019 July 26]. Available from: https://publications.europa.eu/en/publicationdetail/-/publication/2f01a3d1-0af2-11e8-966a-01aa75ed71a1/language-en.

4. Nyman AL, Sterling KL, Weaver SR, Majeed BA, Eriksen MP. Little Cigars and Cigarillos: Users, Perceptions, and Reasons for Use. Tob Regul Sci. 2016;2(3):239-51. 
5. Gammon DG, Loomis BR, Dench DL, King BA, Fulmer EB, Rogers T. Effect of price changes in little cigars and cigarettes on little cigar sales: USA, Q4 2011-Q4 2013. Tob Control. 2016;25(5):538-44.

6. Messer K, White MM, Strong DR, Wang B, Shi Y, Conway KP, et al. Trends in use of little cigars or cigarillos and cigarettes among U.S smokers, 2002-2011. Nicotine Tob Res. 2015 May;17(5):515-23.

7. JR Blending Room. Difference between a cigarillo and a cigar [Internet]. JR Blending Room [cited 2018 Jan 12]. Available from: https://www.jrcigars.com/blending-room/university/cigars-101/the-difference-betweena-cigarillo-and-a-cigar/2015/11/10/.

8. Vu M, Getachew B, Payne JB, Kirchner TR, Berg CJ. Initiation, continuation of use and cessation of alternative tobacco products among young adults: A qualitative study. Tob Prev Cessat. 2018 Feb;4. pii: 8.

9. Bird Y, May J, Nwankwo C, Mahmood R, Moraros J. Prevalence and characteristics of flavoured tobacco use among students in grades 10 through 12: a national cross-sectional study in Canada, 2012-2013. Tob Induc Dis. 2017 Mar 24;15:20. doi: 10.1186/s12971-017-0124-0.

10. Freiberg MJ. Federal approaches to the regulation of noncigarette tobacco products. Am J Prev Med. 2012 Nov;43(5 Suppl 3):S249-54.

11. Directive 2014/40/eu of the European Parliament and of the Council of 3 April 2014 on the approximation of the laws, regulations and administrative provisions of the Member States concerning the manufacture, presentation and sale of tobacco and related products and repealing Directive 2001/37/EC. Off J Eur Union [Internet]. 2014 Apr 29 [cited 2018 Jan 12];57(L 127):1-38. Available from: https://ec.europa.eu/health// sites/health/files/tobacco/docs/dir_201440_en.pdf.

12. Blank MD, Nasim A, Hart A Jr, Eissenberg T. Acute effects of cigarillo smoking. Nicotine Tob Res. 2011 Sep;13(9):874-9.

13. Truth Tobacco Industry Documents. Cigarillo development [Internet]. Phillip Morris; 1998 [cited 2018 Jan 12]. Available from: https://www. industrydocumentslibrary.ucsf.edu/tobacco/docs/\#id=spcx 0076 .

14. European Commission. Excise duties on tobacco. Cigarettes [Internet]. [cited 2018 Jan 12]. Available from: https://ec.europa.eu/taxation_customs/business/excise-duties-alcohol-tobacco-energy/excise-dutiestobacco/excise-duties-cigarettes_en.

15. Delnevo CD. Smokers' choice: what explains the steady growth of cigar use in the U.S.? Public Health Rep. 2006;121(2):116-9.

16. Euromonitor International [Internet]. [cited 2018 Oct 16]. Available from: https://www.euromonitor.com/
17. Filippidis FT, Laverty AA, Hone T, Been JV, Millett C. Association of cigarette price differentials with infant mortality in 23 European Union countries. JAMA Pediatr. 2017 Nov 1;1;171(11):1100-6.

18. Yeh CY, Schafferer C, Lee JM, Ho LM, Hsieh CJ. The effects of a rise in cigarette price on cigarette consumption, tobacco taxation revenues, and of smoking-related deaths in $28 \mathrm{EU}$ countries - applying threshold regression modelling. BMC Public Health. 2017 Sep 21;17(1):676. doi: 10.1186/s12889-017-4685-x

19. Blecher EH, Van Walbeek CP. An international analysis of cigarette affordability. Tob Control. 2004;13(4):339-46.

20. Eurostat [Internet]. [cited 2018 Oct 16]. Available from: https://ec.europa. eu/eurostat.

21. Richardson A, Xiao H, Vallone DM. Primary and dual users of cigars and cigarettes: profiles, tobacco use patterns and relevance to policy. Nicotine Tob Res. 2012;14(8):927-32.

22. Agaku IT, Filippidis FT, Vardavas CI, Odukoya OO, Awopegba AJ, AyoYusuf OA, et al. Poly-tobacco use among adults in 44 countries during 2008-2012: evidence for an integrative and comprehensive approach in tobacco control. Drug Alcohol Depend. 2014;139:60-70.

23. WHO report on the global tobacco epidemic, 2015: raising taxes on tobacco. Geneva: WHO; 2015.

24. Agaku IT, Filippidis FT, Vardavas CI. Effectiveness of text versus pictorial health warning labels and predictors of support for plain packaging of tobacco products within the European Union. Eur Addict Res. 2015;21(1):47-52.

25. Truth Tobacco Industry Documents. Simba concept test [Internet]. Philip Morris; 1994 [cited 2018 Apr 3]. Available from: https://www.industrydocuments.ucsf.edu/tobacco/results/\#q=Simba\%20 concept\%20test\&h= $\% 7 \mathrm{~B} \% 22$ hideDuplicates $\% 22 \% 3$ Atrue $\% 2 \mathrm{C} \% 22$ hideFolders $\% 22 \% 3$ Atru $\mathrm{e} \% 7 \mathrm{D} \&$ subsite $=$ tobacco\&cache $=$ true $\&$ count $=112$.

26. Truth Tobacco Industry Documents. Marlboro 10's in-depth interviews [Internet]. Philip Morris; 1995 [cited 2018 Apr 3]. Available from: https:// www.industrydocuments.ucsf.edu/tobacco/results/ $\# \mathrm{q}=950817 \& \mathrm{~h}=\% 7 \mathrm{~B}$ $\% 22$ hideDuplicates $\% 22 \% 3$ Atrue $\% 2 \mathrm{C} \% 22$ hideFolders $\% 22 \% 3$ Atrue $\% 7$ D\&subsite $=$ tobacco\&cache $=$ true \&count $=100$.

Received October 30, 2018 Accepted in revised form July 27, 2019 